\title{
Prognostic Nomograms based on Homogeneous and Heterogeneous Associated Factors for Predicting the Overall Survival of Colorectal Cancer Patients with Distant Metastases
}

\section{Hongmei Wang ( $\square$ wanghongmei225@126.com )}

The First Affiliated Hospital of Chongqing Medical University https://orcid.org/0000-0001-5678-1967

\section{Xuefeng Shan}

The First Affiliated Hospital of Chongqing Medical University

min zhang

The First Affiliated Hospital of Chongqing Medical University

\section{Kun Qian}

The First Affiliated Hospital of Chongqing Medical University

\section{Weiying Zhou}

Chongqing Medical University

\section{Research}

Keywords: Colorectal cancer, Metastases, Survival, SEER, Nomogram

Posted Date: June 21st, 2021

DOI: https://doi.org/10.21203/rs.3.rs-600814/v1

License: (c) (i) This work is licensed under a Creative Commons Attribution 4.0 International License.

Read Full License 


\section{Abstract}

Background: To identify the heterogeneous and homogeneous prognostic factors associated with distant metastases in colorectal cancer (CRC) patients and then construct nomograms to predict prognosis.

Methods: CRC patients registered in the Surveillance, Epidemiology, and End Results (SEER) database between 2010 and 2016 were included. Cox regression was used to analyse homogeneous and heterogeneous prognostic factors, and Kaplan-Meier analysis was used to estimate overall survival (OS). Predictive nomograms were constructed, and their performance was evaluated with C-indexes and calibration curves.

Results: A total of 34933 patients with distant metastases were included. The median survival time of patients with liver metastases, lung metastases, bone metastases, and brain metastases were 12.00 months (95\% Cl: 11.71-12.29 months), 10.00 months (95\% Cl: $9.57-10.43$ months), 5.00 months (95\% Cl: 4.47-5.53 months), and 3.00 months (95\% Cl: 2.31-3.70 months), respectively. Older age and no surgery were identified as homogeneous prognostic factors of the four types of metastases. Male sex, black race, unmarried status, uninsured status, primary CRC site, poor differentiation/grade, advanced N stage, $\mathrm{T}$ stage, high carcinoembryonic antigen (CEA) level and metastatic organ were heterogeneously associated with the prognosis of patients with distant metastases. The calibration curves and C-indexes exhibited good performance for predicting the OS of patients with distant metastases.

Conclusion: $\mathrm{CRC}$ patients with distant metastases exhibited homogeneous and heterogeneous prognostic factors, all of which were associated with poor survival. The nomograms showed good accuracy and can be used as tools for clinicians to predict the prognosis of CRC patients with distant metastases.

\section{Background}

Colorectal cancer (CRC) is the third most commonly diagnosed cancer and the second leading cause of cancer-related death worldwide [1]. Approximately $20 \%$ of patients with CRC have distant metastases at initial diagnosis [2], and these patients have a lower 1-year and 5-year cancer-specific survival rate than patients without distant metastases [3-5]. However, due to the heterogeneity of metastatic patterns, CRC patients with specific organ metastases experience different prognoses; for instance, CRC patients with brain metastases have worse 5 -year survival than those with liver metastases $(0.4 \%$ vs. $16.9 \%)[6,7]$. The early detection of prognostic factors for CRC with distant metastases may help predict the probability of survival. However, the survival of CRC patients with distant metastases and the prognostic factors for their specific organ metastases are still unclear.

To our knowledge, some studies have investigated the prognostic factors of distant metastases in CRC, but majority of them have focused on patients who have already received treatments [8-10]. In addition, only a few studies described models to predict the survival of CRC patients with distant metastases [11, 12], and the results remain controversial due to the limited sample size. Moreover, homogeneous and 
heterogeneous prognostic risk factors for CRC patients with specific organ metastases have not yet been explored.

Therefore, this study aimed to characterize the differences in prognostic factors based on a large population cohort of CRC patients with distant metastases. Furthermore, a nomogram was developed to predict the prognosis of CRC patients with specific organ metastases and provide a reference tool for clinicians to guide individualized treatment for CRC patients.

\section{Methods}

\section{Population}

In the present study, CRC patient data were acquired from the US National Cancer Institute ( $\mathrm{NCl})$ open public database, the Surveillance, Epidemiology, and End Results (SEER) database. This study included CRC patients diagnosed between 2010 and 2016. Patients were excluded if they were diagnosed at autopsy or via a death certificate, if the follow-up was unspecified, if the site of the primary tumour was not in the colorectal region, or if information on distant metastases was unavailable. This study used SEER*Stat version 8.3.5 (https://seer.cancer.gov/seerstat/) (Information Management Service, Inc. Calverton, MD, USA) to generate the patient list.

\section{Statistical analysis}

Quantitative data are presented as the mean \pm standard deviation (SD), and categorical data are described as the number and percentage $(\mathrm{N}, \%)$. Univariable and multivariable Cox regression analyses were conducted to identify potentially associated prognostic factors. Based on the results of the Cox regression analysis, the intersection of the prognostic factors for the four types of metastases was used to identify homogenous or heterogeneous factors. The Kaplan-Meier method was used to estimate overall survival (OS). Based on the results of the multivariable Cox regression analysis, predictive nomograms for liver, lung, bone, and brain metastases were formulated. C-indexes and calibration curves were used to evaluate their distinguishing and predictive abilities. Statistically significant levels were twotailed and set at $p<0.05$. Statistical analyses were conducted with the IBM Statistical Package for the Social Sciences (SPSS) version 23.0 software package for Windows (SPSS, Inc., Chicago, IL, USA). The nomogram was plotted using the "rms", "Hmisc", and "survival" packages in R version 3.4.1 (R Foundation for Statistical Computing, Vienna, Austria; www.r-project.org).

\section{Results}

\section{Demographic and clinical characteristics}

A total of 34933 patients with distant metastases and 31288 patients with liver metastases, 10598 patients with lung metastases, 2553 patients with bone metastases, and 587 patients with brain metastases were included in this study. The detailed workflow for patient selection is shown in Fig. 1. The 
mean age of all 34933 CRC patients with distant metastases was $64.19 \pm 14.13$ years (range 14 to 108 ), $55.2 \%$ of patients $(N=19273)$ were male, and $44.8 \%$ of patients $(N=15660)$ were female. Most of the patients were white $(75.1 \%, N=26234)$, followed by black $(15.5 \%, N=5400)$. Forty-eight percent $(\mathrm{N}=$ 16944) of patients were married, and $77.7 \%(\mathrm{~N}=27152)$ were insured. Regarding the primary tumour sites, most were localized in the left colon $(35.70 \%, N=12470)$ and right colon $(35.17 \%, N=12285)$, followed by the rectum $(20.31 \%, N=7098)$. A total of $30.38 \%(N=10612)$ of patients were initially diagnosed with a stage $\mathrm{T} 3$ tumour, and $47.23 \%(\mathrm{~N}=16498)$ were diagnosed with a grade II tumour. Detailed demographic and clinical characteristics are shown in Table 1. 
Table 1

Patient characteristics and 1-, 3-, and 5-year overall survival rates for colorectal cancer with distant metastases

\begin{tabular}{|c|c|c|c|c|c|}
\hline \multirow[t]{2}{*}{ Subject characteristics } & \multicolumn{5}{|c|}{ CRC patients with distant metastases $(\mathrm{N}=34933$ ) } \\
\hline & $\mathbf{N}$ & $\%$ & 1-year (\%) & 3-year (\%) & 5-year (\%) \\
\hline \multicolumn{6}{|l|}{ Age(years) } \\
\hline$\leq 50$ & 5936 & 17.0 & 69.4 & 28.9 & 15.1 \\
\hline $51-60$ & 8382 & 24.0 & 60.4 & 24.9 & 12.2 \\
\hline $61-70$ & 9035 & 25.9 & 52.1 & 25.8 & 10.2 \\
\hline $71-80$ & 6460 & 18.5 & 38.1 & 12.3 & 6.1 \\
\hline $81-90$ & 4269 & 12.2 & 20.8 & 4.2 & 2.1 \\
\hline$\geq 91$ & 851 & 2.4 & 8.7 & 1.6 & 0 \\
\hline \multicolumn{6}{|l|}{ Sex } \\
\hline Female & 15660 & 44.8 & 47.1 & 18.5 & 9.7 \\
\hline Male & 19273 & 55.2 & 51.4 & 19.2 & 9.3 \\
\hline \multicolumn{6}{|l|}{ Race } \\
\hline White & 26234 & 75.1 & 49.6 & 19.5 & 9.9 \\
\hline Black & 5400 & 15.5 & 46.7 & 14.7 & 6.8 \\
\hline Others ${ }^{a}$ & 3205 & 9.2 & 52.9 & 20.7 & 10.4 \\
\hline Unknown & 94 & 0.3 & 66.7 & 40.0 & 26.7 \\
\hline \multicolumn{6}{|l|}{ Marital status } \\
\hline Married & 16944 & 48.5 & 56.2 & 23.0 & 11.8 \\
\hline Unmarried $^{b}$ & 16189 & 46.3 & 42.5 & 14.7 & 7.0 \\
\hline Unknown & 1800 & 5.2 & 48.7 & 18.7 & 10.2 \\
\hline \multicolumn{6}{|l|}{ Insurance status } \\
\hline Insured & 27152 & 77.7 & 50.4 & 20.0 & 10.2 \\
\hline \multicolumn{6}{|c|}{ Abbreviations: CEA = carcinoembryonic antigen; Surg(pri) = surgical treatments of primary site } \\
\hline \multicolumn{6}{|c|}{ a Includes American Indian/Alaska Native and Asian or Pacific Islander } \\
\hline \multicolumn{6}{|c|}{ b Includes single, separated, widowed, and divorced } \\
\hline c Sites were unclear & & & & & \\
\hline
\end{tabular}




\begin{tabular}{|c|c|c|c|c|c|}
\hline \multirow[t]{2}{*}{ Subject characteristics } & \multicolumn{5}{|c|}{ CRC patients with distant metastases $(\mathrm{N}=34933)$} \\
\hline & $\mathbf{N}$ & $\%$ & 1-year (\%) & 3-year (\%) & 5-year (\%) \\
\hline Any medic aid & 6045 & 17.3 & 45.4 & 14.3 & 6.4 \\
\hline Uninsured & 1736 & 5.0 & 48.7 & 17.9 & 8.5 \\
\hline \multicolumn{6}{|l|}{ Site } \\
\hline Right coon & 12285 & 35.2 & 43.3 & 14.3 & 7.4 \\
\hline Left colon & 12470 & 35.7 & 57.4 & 24.6 & 12.4 \\
\hline Rectum & 7098 & 20.3 & 58.4 & 22.9 & 11.1 \\
\hline Unknown & 3080 & 8.8 & 21.5 & 5.1 & 2.7 \\
\hline \multicolumn{6}{|l|}{ Histological grade } \\
\hline Grade I & 1420 & 4.1 & 60.8 & 27.5 & 14.6 \\
\hline Grade II & 16498 & 47.2 & 63.4 & 26.2 & 13.5 \\
\hline Grade III & 5496 & 15.7 & 41.6 & 13.7 & 6.5 \\
\hline Grade IV & 1037 & 3.0 & 38.3 & 13.6 & 5.9 \\
\hline Unknown & 10482 & 30.0 & 31.2 & 9.3 & 4.3 \\
\hline \multicolumn{6}{|l|}{ Lymphatic metastasis } \\
\hline NO & 11445 & 32.8 & 45.8 & 18.2 & 10.1 \\
\hline N1 & 11055 & 31.6 & 57.0 & 24.0 & 12.1 \\
\hline N2 & 7034 & 20.1 & 58.5 & 21.3 & 9.6 \\
\hline Unknown & 5399 & 15.5 & 29.8 & 7.0 & 2.9 \\
\hline \multicolumn{6}{|l|}{ T stage } \\
\hline T1 & 3267 & 9.4 & 42.8 & 12.4 & 5.1 \\
\hline T2 & 735 & 2.1 & 66.9 & 37.0 & 25.1 \\
\hline T3 & 10612 & 30.4 & 67.2 & 31.3 & 16.9 \\
\hline T4 & 7962 & 22.8 & 51.3 & 18.0 & 8.2 \\
\hline \multicolumn{6}{|c|}{ Abbreviations: $C E A$ = carcinoembryonic antigen; Surg $(\mathrm{pri})$ = surgical treatments of primary site } \\
\hline \multicolumn{6}{|c|}{ a Includes American Indian/Alaska Native and Asian or Pacific Islander } \\
\hline \multicolumn{6}{|c|}{ b Includes single, separated, widowed, and divorced } \\
\hline c Sites were unclear & & & & & \\
\hline
\end{tabular}




\begin{tabular}{|llllll|}
\hline Subject characteristics & \multicolumn{5}{c|}{ CRC patients with distant metastases (N=34933) } \\
\cline { 2 - 6 } & $\mathbf{N}$ & $\%$ & 1-year (\%) & 3-year (\%) & 5-year (\%) \\
\hline Unknown & 12357 & 35.4 & 32.9 & 8.5 & 3.5 \\
\hline CEA & & & & & \\
\hline Negative & 3499 & 10.0 & 64.1 & 33.6 & 21.3 \\
\hline Positive & 20199 & 57.8 & 51.7 & 17.4 & 7.9 \\
\hline Unknown & 11235 & 32.2 & 42.8 & 16.9 & 8.7 \\
\hline Surg(pri) & & & & & 16.8 \\
\hline Yes & 15634 & 44.8 & 66.4 & 31.0 & 3.1 \\
\hline None & 19190 & 54.9 & 35.5 & 8.5 & 10.5 \\
\hline Unknown & 109 & 0.3 & 36.8 & 14.7 & \\
\hline Abbreviations: CEA = carcinoembryonic antigen; Surg(pri) = surgical treatments of primary site. & \\
\hline a Includes American Indian/Alaska Native and Asian or Pacific Islander & \\
\hline b Includes single, separated, widowed, and divorced & \\
\hline c Sites were unclear & & & \\
\hline
\end{tabular}

\section{Survival Outcomes In Patients With Distant Metastases}

The 1-, 3-, and 5-year OS rates were $49.5 \%, 18.9 \%$, and $9.5 \%$ for all patients, respectively. The mean survival time was 20.94 months. The 1-, 3-, and 5-year OS rates rapidly decreased with increasing age. However, the 1-, 3-, and 5-year OS rates in patients who underwent surgery at the primary site were much higher than those in patients who did not $(p<0.001)$. The detailed data of the patients' $1-, 3-$, and 5-year OS rates are listed in Table 1, and the median survival times are listed in Table 2. 
Table 2

Multivariable Cox regression for analyzing the prognosis factors for colorectal cancer with distant metastases.

\begin{tabular}{|c|c|c|c|c|c|c|}
\hline \multirow{2}{*}{$\begin{array}{l}\text { Subject } \\
\text { characteristics }\end{array}$} & \multirow{2}{*}{$\begin{array}{l}\text { No. of CRC } \\
\text { patients with } \\
\text { distant } \\
\text { metastases }\end{array}$} & \multirow{2}{*}{$\begin{array}{l}\text { Survival } \\
\text { median, } \\
\text { months }\end{array}$} & \multicolumn{2}{|l|}{ Univariate } & \multicolumn{2}{|l|}{ Multivariate } \\
\hline & & & $\mathrm{HR}(95 \% \mathrm{Cl})$ & $\begin{array}{l}\mathrm{P}- \\
\text { value }\end{array}$ & $\mathrm{HR}(95 \% \mathrm{Cl})$ & $\begin{array}{l}P- \\
\text { value }\end{array}$ \\
\hline \multicolumn{7}{|l|}{ Age (years) } \\
\hline$\leq 50$ & 5936 & $\begin{array}{l}22.00(21.25- \\
22.75)\end{array}$ & 1(Reference) & 1.00 & 1(Reference) & 1.00 \\
\hline $51-60$ & 8382 & $\begin{array}{l}18.00(17.39- \\
18.61)\end{array}$ & $\begin{array}{l}1.20(1.15- \\
1.25)\end{array}$ & $<0.001$ & $\begin{array}{l}1.15(1.10- \\
1.20)\end{array}$ & $<0.001$ \\
\hline $61-70$ & 9035 & $\begin{array}{l}14.00(13.42- \\
14.58)\end{array}$ & $\begin{array}{l}1.44(1.38- \\
1.5)\end{array}$ & $<0.001$ & $\begin{array}{l}1.38(1.32- \\
1.44)\end{array}$ & $<0.001$ \\
\hline $71-80$ & 6460 & $\begin{array}{l}7.00(6.55- \\
7.45)\end{array}$ & $\begin{array}{l}2.02(1.93- \\
2.1)\end{array}$ & $<0.001$ & $\begin{array}{l}1.93(1.85- \\
2.01)\end{array}$ & $<0.001$ \\
\hline $81-90$ & 4269 & $\begin{array}{l}3.00(2.78- \\
3.22)\end{array}$ & $\begin{array}{l}3.25(3.1- \\
3.4)\end{array}$ & $<0.001$ & $\begin{array}{l}2.79(2.66- \\
2.93)\end{array}$ & $<0.001$ \\
\hline$\geq 91$ & 851 & $\begin{array}{l}1.00(0.74- \\
1.26)\end{array}$ & $\begin{array}{l}5.00(4.63- \\
5.4)\end{array}$ & $<0.001$ & $\begin{array}{l}3.62(3.34- \\
3.92)\end{array}$ & $<0.001$ \\
\hline \multicolumn{7}{|l|}{ Sex } \\
\hline Female & 15660 & $\begin{array}{l}11.00(10.59- \\
11.41)\end{array}$ & 1(Reference) & 1.00 & 1(Reference) & 1.00 \\
\hline Male & 19273 & $\begin{array}{l}13.00(12.62- \\
13.38)\end{array}$ & $\begin{array}{l}0.93(0.91- \\
0.96)\end{array}$ & $<0.001$ & $\begin{array}{l}1.07(1.04- \\
1.1)\end{array}$ & $<0.001$ \\
\hline \multicolumn{7}{|l|}{ Race } \\
\hline White & 26234 & $\begin{array}{l}12.00(11.67- \\
12.33)\end{array}$ & 1(Reference) & 1.00 & 1(Reference) & 1.00 \\
\hline Black & 5400 & $\begin{array}{l}11.00(10.38- \\
11.62)\end{array}$ & $\begin{array}{l}1.12(1.08- \\
1.16)\end{array}$ & $<0.001$ & $\begin{array}{l}1.10(1.07- \\
1.14)\end{array}$ & $<0.001$ \\
\hline Others ${ }^{a}$ & 3205 & $\begin{array}{l}14.00(12.91- \\
15.09)\end{array}$ & $\begin{array}{l}0.91(0.88- \\
0.96)\end{array}$ & $<0.001$ & $\begin{array}{l}0.97(0.92- \\
1.01)\end{array}$ & 0.133 \\
\hline Unknown & 94 & $\begin{array}{l}25.00(13.41- \\
36.59)\end{array}$ & $\begin{array}{l}0.58(0.42- \\
0.79)\end{array}$ & 0.001 & $\begin{array}{l}0.57(0.41- \\
0.78)\end{array}$ & 0.001 \\
\hline
\end{tabular}

Abbreviations: $\mathrm{CEA}=$ carcinoembryonic antigen, $N A=$ not available, $\mathrm{Surg}($ pri $)=$ surgical treatments of primary site.

a Includes American Indian/Alaska Native and Asian or Pacific Islander.

b Includes single, separated, widowed, and divorced. 


\begin{tabular}{|c|c|c|c|c|c|c|}
\hline \multirow{2}{*}{$\begin{array}{l}\text { Subject } \\
\text { characteristics }\end{array}$} & \multirow{2}{*}{$\begin{array}{l}\text { No. of CRC } \\
\text { patients with } \\
\text { distant } \\
\text { metastases }\end{array}$} & \multirow{2}{*}{$\begin{array}{l}\text { Survival } \\
\text { median, } \\
\text { months }\end{array}$} & \multicolumn{2}{|l|}{ Univariate } & \multicolumn{2}{|l|}{ Multivariate } \\
\hline & & & $\mathrm{HR}(95 \% \mathrm{Cl})$ & $\begin{array}{l}\mathrm{P}- \\
\text { value }\end{array}$ & $\mathrm{HR}(95 \% \mathrm{Cl})$ & $\begin{array}{l}\mathrm{P}- \\
\text { value }\end{array}$ \\
\hline \multicolumn{7}{|l|}{ Marital status } \\
\hline Married & 16189 & $\begin{array}{l}16.00(15.55- \\
16.45)\end{array}$ & 1(Reference) & 1.00 & 1(Reference) & 1.00 \\
\hline Unmarried $^{b}$ & 16944 & $\begin{array}{l}9.00(8.64- \\
9.36)\end{array}$ & $\begin{array}{l}1.37(1.34- \\
1.41)\end{array}$ & $<0.001$ & $\begin{array}{l}1.20(1.17- \\
1.23)\end{array}$ & $<0.001$ \\
\hline Unknown & 1800 & $\begin{array}{l}12.00(10.6- \\
13.4)\end{array}$ & $\begin{array}{l}1.18(1.11- \\
1.25)\end{array}$ & $<0.001$ & $\begin{array}{l}1.09(1.03- \\
1.15)\end{array}$ & 0.005 \\
\hline \multicolumn{7}{|l|}{$\begin{array}{l}\text { Insurance } \\
\text { status }\end{array}$} \\
\hline Insured & 27152 & $\begin{array}{l}13.00(12.67- \\
13.33)\end{array}$ & 1(Reference) & 1.00 & 1(Reference) & 1.00 \\
\hline Any medic aid & 1736 & $\begin{array}{l}11.00(10.44- \\
11.56)\end{array}$ & $\begin{array}{l}1.15(1.11- \\
1.19)\end{array}$ & $<0.001$ & $\begin{array}{l}1.24(1.19- \\
1.28)\end{array}$ & $<0.001$ \\
\hline Uninsured & 6045 & $\begin{array}{l}12.00(10.68- \\
13.32)\end{array}$ & $\begin{array}{l}1.05(0.99- \\
1.11)\end{array}$ & 0.082 & $\begin{array}{l}1.30(1.23- \\
1.38)\end{array}$ & $<0.001$ \\
\hline \multicolumn{7}{|l|}{ Site } \\
\hline Right colon & 12285 & $\begin{array}{l}10.00(9.61- \\
10.39)\end{array}$ & 1(Reference) & 1.00 & 1(Reference) & 1.00 \\
\hline Left colon & 12470 & $\begin{array}{l}17.00(16.45- \\
17.55)\end{array}$ & $\begin{array}{l}0.71(0.69- \\
0.73)\end{array}$ & $<0.001$ & $\begin{array}{l}0.78(0.76- \\
0.80)\end{array}$ & $<0.001$ \\
\hline Rectum & 7098 & $\begin{array}{l}17.00(16.3- \\
17.7)\end{array}$ & $\begin{array}{l}0.71(0.68- \\
0.73)\end{array}$ & $<0.001$ & $\begin{array}{l}0.66(0.63- \\
0.68)\end{array}$ & $<0.001$ \\
\hline Unknown & 3080 & $\begin{array}{l}2.00(1.74- \\
2.26)\end{array}$ & $\begin{array}{l}1.79(1.71- \\
1.86)\end{array}$ & $<0.001$ & $\begin{array}{l}1.13(1.08- \\
1.19)\end{array}$ & $<0.001$ \\
\hline \multicolumn{7}{|l|}{$\begin{array}{l}\text { Histological } \\
\text { grade }\end{array}$} \\
\hline Grade I & 1420 & $\begin{array}{l}19.00(17.03- \\
20.97)\end{array}$ & 1(Reference) & 1.00 & 1(Reference) & 1.00 \\
\hline Grade II & 16498 & $\begin{array}{l}20.00(19.54- \\
20.46)\end{array}$ & $\begin{array}{l}0.99(0.93- \\
1.06)\end{array}$ & 0.821 & $\begin{array}{l}1.10(1.03- \\
1.18)\end{array}$ & 0.005 \\
\hline
\end{tabular}

Abbreviations: $\mathrm{CEA}=$ carcinoembryonic antigen, $N A=$ not available, $\mathrm{Surg}($ pri $)=$ surgical treatments of primary site.

a Includes American Indian/Alaska Native and Asian or Pacific Islander.

b Includes single, separated, widowed, and divorced. 


\begin{tabular}{|c|c|c|c|c|c|c|}
\hline \multirow{2}{*}{$\begin{array}{l}\text { Subject } \\
\text { characteristics }\end{array}$} & \multirow{2}{*}{$\begin{array}{l}\text { No. of CRC } \\
\text { patients with } \\
\text { distant } \\
\text { metastases }\end{array}$} & \multirow{2}{*}{$\begin{array}{l}\text { Survival } \\
\text { median, } \\
\text { months }\end{array}$} & \multicolumn{2}{|l|}{ Univariate } & \multicolumn{2}{|l|}{ Multivariate } \\
\hline & & & $\mathrm{HR}(95 \% \mathrm{Cl})$ & $\begin{array}{l}P- \\
\text { value }\end{array}$ & HR (95\% Cl) & $\begin{array}{l}\mathrm{P}- \\
\text { value }\end{array}$ \\
\hline Grade III & 5496 & $\begin{array}{l}9.00(8.52- \\
9.48)\end{array}$ & $\begin{array}{l}1.62(1.51- \\
1.74)\end{array}$ & $<0.001$ & $\begin{array}{l}1.72(1.6- \\
1.85)\end{array}$ & $<0.001$ \\
\hline Grade IV & 1037 & $\begin{array}{l}8.00(6.99- \\
9.01)\end{array}$ & $\begin{array}{l}1.68(1.53- \\
1.85)\end{array}$ & $<0.001$ & $\begin{array}{l}1.92(1.74- \\
2.11)\end{array}$ & $<0.001$ \\
\hline Unknown & 10482 & $\begin{array}{l}5.00(4.73- \\
5.27)\end{array}$ & $\begin{array}{l}2.15(2.01- \\
2.3)\end{array}$ & $<0.001$ & $\begin{array}{l}1.40(1.3- \\
1.5)\end{array}$ & $<0.001$ \\
\hline \multicolumn{7}{|l|}{$\begin{array}{l}\text { Lymphatic } \\
\text { metastasis }\end{array}$} \\
\hline NO & 11445 & $\begin{array}{l}10.00(9.51- \\
10.49)\end{array}$ & 1(Reference) & 1.00 & 1(Reference) & 1.00 \\
\hline N1 & 11055 & $\begin{array}{l}16.00(15.41- \\
16.59)\end{array}$ & $\begin{array}{l}0.78(0.76- \\
0.81)\end{array}$ & $<0.001$ & $\begin{array}{l}1.06(1.03- \\
1.10)\end{array}$ & $<0.001$ \\
\hline N2 & 7034 & $\begin{array}{l}17.00(16.38- \\
17.62)\end{array}$ & $\begin{array}{l}0.80(0.77- \\
0.83)\end{array}$ & $<0.001$ & $\begin{array}{l}1.36(1.30- \\
1.42)\end{array}$ & $<0.001$ \\
\hline Unknown & 5399 & $\begin{array}{l}5.00(4.66- \\
5.34)\end{array}$ & $\begin{array}{l}1.56(1.5- \\
1.62)\end{array}$ & $<0.001$ & $\begin{array}{l}1.13(1.09- \\
1.18)\end{array}$ & $<0.001$ \\
\hline \multicolumn{7}{|l|}{ T stage } \\
\hline T1 & 3267 & $\begin{array}{l}9.00(8.27- \\
9.73)\end{array}$ & 1(Reference) & 1.00 & 1(Reference) & 1.00 \\
\hline T2 & 735 & $\begin{array}{l}24.00(20.78- \\
27.22)\end{array}$ & $\begin{array}{l}0.47(0.43- \\
0.52)\end{array}$ & $<0.001$ & $\begin{array}{l}0.74(0.67- \\
0.83)\end{array}$ & $<0.001$ \\
\hline Т3 & 10612 & $\begin{array}{l}22.00(21.35- \\
22.65)\end{array}$ & $\begin{array}{l}0.53(0.51- \\
0.56)\end{array}$ & $<0.001$ & $\begin{array}{l}0.81(0.77- \\
0.85)\end{array}$ & $<0.001$ \\
\hline T4 & 7962 & $\begin{array}{l}13.00(12.47- \\
13.53)\end{array}$ & $\begin{array}{l}0.80(0.77- \\
0.84)\end{array}$ & $<0.001$ & $\begin{array}{l}1.08(1.03- \\
1.14)\end{array}$ & 0.002 \\
\hline Unknown & 12357 & $\begin{array}{l}5.00(4.72- \\
5.28)\end{array}$ & $\begin{array}{l}1.28(1.22- \\
1.33)\end{array}$ & $<0.001$ & $\begin{array}{l}1.03(0.98- \\
1.07)\end{array}$ & 0.246 \\
\hline \multicolumn{7}{|l|}{ CEA } \\
\hline Negative & 3499 & $\begin{array}{l}22.00(20.68- \\
23.32)\end{array}$ & 1(Reference) & 1.00 & 1 (Reference) & 1.00 \\
\hline
\end{tabular}

Abbreviations: $\mathrm{CEA}=$ carcinoembryonic antigen, $N A=$ not available, $\mathrm{Surg}($ pri $)=$ surgical treatments of primary site.

a Includes American Indian/Alaska Native and Asian or Pacific Islander.

b Includes single, separated, widowed, and divorced. 


\begin{tabular}{|c|c|c|c|c|c|c|}
\hline \multirow{2}{*}{$\begin{array}{l}\text { Subject } \\
\text { characteristics }\end{array}$} & \multirow{2}{*}{$\begin{array}{l}\text { No. of CRC } \\
\text { patients with } \\
\text { distant } \\
\text { metastases }\end{array}$} & \multirow{2}{*}{$\begin{array}{l}\text { Survival } \\
\text { median, } \\
\text { months }\end{array}$} & \multicolumn{2}{|l|}{ Univariate } & \multicolumn{2}{|l|}{ Multivariate } \\
\hline & & & $\mathrm{HR}(95 \% \mathrm{Cl})$ & $\begin{array}{l}\text { P- } \\
\text { value }\end{array}$ & $\mathrm{HR}(95 \% \mathrm{Cl})$ & $\begin{array}{l}\mathrm{P}- \\
\text { value }\end{array}$ \\
\hline Positive & 20199 & $\begin{array}{l}13.00(12.65- \\
13.35)\end{array}$ & $\begin{array}{l}1.56(1.49- \\
1.63)\end{array}$ & $<0.001$ & $\begin{array}{l}1.38(1.32- \\
1.45)\end{array}$ & $<0.001$ \\
\hline Unknown & 11235 & $\begin{array}{l}9.00(8.55- \\
9.45)\end{array}$ & $\begin{array}{l}1.78(1.7- \\
1.87)\end{array}$ & $<0.001$ & $\begin{array}{l}1.45(1.38- \\
1.52)\end{array}$ & $<0.001$ \\
\hline \multicolumn{7}{|l|}{ Surg(pri) } \\
\hline Yes & 15634 & $\begin{array}{l}22.00(21.47- \\
22.53)\end{array}$ & 1(Reference) & 1.00 & 1(Reference) & 1.00 \\
\hline None & 19190 & $\begin{array}{l}7.00(6.76- \\
7.24)\end{array}$ & $\begin{array}{l}2.27(2.21- \\
2.33)\end{array}$ & $<0.001$ & $\begin{array}{l}2.17(2.09- \\
2.26)\end{array}$ & $<0.001$ \\
\hline Unknown & 109 & $\begin{array}{l}7.00(2.87- \\
11.13)\end{array}$ & $\begin{array}{l}1.81(1.45- \\
2.25)\end{array}$ & $<0.001$ & $\begin{array}{l}1.53(1.23- \\
1.91)\end{array}$ & $<0.001$ \\
\hline \multicolumn{7}{|c|}{$\begin{array}{l}\text { Abbreviations: } C E A=\text { carcinoembryonic antigen, } N A=\text { not available, Surg }(\text { pri })=\text { surgical treatments of } \\
\text { primary site. }\end{array}$} \\
\hline \multicolumn{7}{|c|}{ a Includes American Indian/Alaska Native and Asian or Pacific Islander. } \\
\hline b Includes sinc & eparated, w & ed, and divo & & & & \\
\hline
\end{tabular}

The median survival times of patients with liver metastases, lung metastases, bone metastases, and brain metastases were 12.00 months ( $95 \% \mathrm{Cl}$ : $11.71-12.29$ months), 10.00 months ( $95 \% \mathrm{Cl}$ : $9.57-10.43$ months), 5.00 months ( $95 \% \mathrm{Cl}: 4.47-5.53$ months), and 3.00 months (95\% Cl: $2.31-3.70$ months), respectively, with a significant difference $(p<0.001)$ (Fig. 2). The 1-year survival rate was highest for patients with liver metastases (49.1\%), followed by those with lung metastases (44.2\%), bone metastases (29.3\%), and brain metastases (26.0\%). The 3-year survival rates for patients with liver metastasis and lung metastases were $18.4 \%$ and $13.5 \%$, respectively, which were higher than those for patients with bone metastases (7.0\%) and brain metastases (5.1\%). The 5-year survival rates for patients with liver metastases (9.2\%), lung metastases (5.2\%), bone metastases (3.0\%), and brain metastases (3.6\%) were all poor and lower than $10 \%$. Details on the 1-, 3-, and 5-year OS rates of CRC patients with liver metastases, lung metastases, bone metastases and brain metastases are listed in Tables S1-S4.

\section{Prognostic Factors In Crc Patients With Distant Metastases}

Age, sex, race, marital status, insurance status, primary tumour site, histological grade, lymphatic metastasis, $T$ stage, carcinoembryonic antigen (CEA) level and surgical treatment at the primary site were correlated with the prognosis of patients with distant metastases in the univariate analysis. The results of the multivariable model indicated that older age, male sex, black race, unmarried status, uninsured status, poor histological grade, stage T4/T1, high CEA level and no surgical treatment all showed positive associations with the prognosis of patients with metastases (see Table 2). The associated prognostic 
factors and their HRs with 95\% Cls according to the different sites of metastases are presented in Tables S5-S8.

The prognostic factors associated with CRC with metastases at different organs were homogeneous and heterogeneous. Both older age and no surgery at the primary site showed positive associations with the prognosis of CRC patients with distant metastases. Male sex, black race, unmarried status, uninsured status, poor histological grade, lymphatic metastasis, stage T4/T1, high CEA level, and metastatic organ showed positive associations with the prognosis of CRC patients with liver metastases. Unmarried status, uninsured status, poor histological grade, lymphatic metastasis, high CEA level, and metastatic organ showed positive associations with the prognosis of CRC patients with lung metastases. Unmarried status, poor histological grade, lymphatic metastasis, and metastatic organ showed positive associations with the prognosis of CRC patients with bone metastases, and high CEA level showed a positive association with the OS of CRC patients with brain metastases (see Fig. 3).

\section{Performance Of The Prognostic And Predictive Nomogram}

All significant variables associated with the prognosis of CRC patients with distant metastases were incorporated into the nomogram for predicting the 1-, 3-, and 5-year OS rates of CRC patients with liver metastases, lung metastases, bone metastases, and brain metastases (Fig. 4(A-D)). The C-indexes for the prediction of the OS of patients with liver metastases, lung metastases, bone metastases, and brain metastases were 74.4\% (95\% Cl, 74.2-74.8\%), 77.6\% (95\% Cl, 77.1-78.1\%), 83.6\% (95\% Cl, 82.8-84.4\%), and $85.3 \%(95 \% \mathrm{Cl}, 83.6-87.1 \%)$, respectively. The calibration curves revealed good agreement between the predicted and observed survival probabilities of CRC patients with liver metastases (Fig. 5A1-A3), lung metastases (Fig. 5B1-B3), bone metastases (Fig. 5C1-C3), and brain metastases (Fig. 5D1-D3).

\section{Discussion}

Recently, majority of studies on the prognosis of CRC patients with distant metastases have shown different results. The results of our study were not entirely consistent with those of some previous studies $[5,13-18,12]$. The 5-year survival rates for CRC patients with liver metastases and lung metastases were $16.9 \%$ [7] and $8.0 \%$ [12], respectively, which were higher than those found in our study. Compared to CRC patients with liver or lung metastases, the prognosis of CRC patients with brain or bone metastases was worse, with a 5 -year survival rate of $<5 \%$. Previous studies reported that the median survival time for CRC patients with bone metastases ranged from 5.0 to 7 months $[16,13,19]$, consistent with our results. However, we found that the median survival time for patients with brain metastases was only three months, which was worse than that reported (from 4.2 to 7 months) [14, 16, 20, 21]. Overall, the OS rates for patients with distant metastases were poor, and the prognosis of CRC patients with brain metastases was the worst, followed by those with bone metastases, lung metastases and liver metastases. This finding is similar to that of a previous study [3]. 
The present study showed that different sites of metastasis exhibited homogeneity and heterogeneity regarding the prognostic factors associated with distant metastases from CRC. To our knowledge, a previous study has not reported these homogeneous prognostic factors (older age, no surgery at the primary site) for the prognosis of CRC patients with distant metastases. This finding will help clinicians tailor targeted preventive treatment strategies, thereby further improving patient survival. Previous studies have mostly focused on the prognosis of CRC patients, and whether age is an independent factor remains controversial. Some studies reported that young patients with CRC had a worse prognosis than older patients [22-24]. Some studies reported the opposite results [25, 26], and another study demonstrated that age was not associated with the prognosis of CRC [27]. This controversy may be due to the limited sample sizes. Our study, based on a large population cohort, showed that older age was a prognostic factor for the four types of metastases. Thus, compared with older patients, younger patients have a better prognosis, consistent with previous reports $[28,29]$. This finding is presumably due to their better physiological reserve and lower incidence of comorbidities. The present study also demonstrated that surgery at the primary site showed a positive association with the four types of metastases (liver, lung, bone, and brain). Many studies on different samples all showed that surgical resection may improve survival. Therefore, when CRC patients are initially diagnosed with distant metastases, surgery at both the primary site and distant lesions may be an appropriate and effective treatment. However, this potential treatment approach still needs to be confirmed through more research.

In addition to these homogeneous factors, some other heterogeneous associated prognostic factors were also found. However, these heterogeneous factors are not completely consistent with those described in previous studies. For instance, both unmarried status and uninsured status showed positive associations with the prognosis of CRC patients with liver metastases, lung metastases and bone metastases. However, these factors have seldom been reported in other studies [12, 30]. One possible reason for the poor prognosis of unmarried or uninsured patients is the lack of mental or financial support from their family members. In addition, the primary site of CRC, a poor differentiation grade, lymphatic metastasis and the metastatic organ were found to be significantly associated with the development of the four types of distant metastases [31]. However, in the present study, these four factors were identified only as homogeneous factors of the prognosis of patients with three types of distant metastases (all except brain metastases). A previous study reported that the tumour site and extracranial metastases were significantly associated with the poor survival of CRC patients with brain metastases [14]. Whether these factors are associated with the prognosis of CRC patients with brain metastases is still controversial, and more studies are needed to confirm this hypothesis.

Additionally, CEA is a widely used biomarker for CRC, and routine monitoring of CEA levels is commonly used to monitor postoperative recurrence and distant metastases [32-34]. A previous study reported that CEA can also be used to predict the prognosis of CRC patients with distant metastases $[12,35,36]$. However, this study showed that CRC patients with bone metastases did not tend to have a significantly poor prognosis when they had a high CEA level. For patients with bone metastases, whether CEA levels affect survival remains to be studied. 
Although some studies have reported prognostic factors for metastatic CRC, the homogeneity and heterogeneity of the prognostic factors of the four types of metastases from CRC have not been comprehensively studied. The homogeneous and heterogeneous associated prognostic factors mentioned in our study may help clinicians guide individualized treatment for patients with metastatic $\mathrm{CRC}$. Based on these prognostic factors, four predictive nomograms were constructed, and all were validated and showed good prediction performance. Similar to the model used to predict distant metastases previously constructed by our team [31], the prognostic and predictive model described herein is also a rapid and cost-effective tool. After screening using our model, patients with metastatic CRC could receive timely targeted therapy to improve their prognosis and avoid other unnecessary expenses.

However, this study still had several limitations. First, distant metastases can be divided into synchronous metastasis and metachronous metastasis. In this study, we investigated the prognostic factors of only synchronous metastasis. Therefore, the results may not be suitable for metachronous metastasis. Second, treatment factors such as chemotherapy and radiotherapy were not incorporated into our study because this information is not available in the SEER database. Last, all of the study participants were from the U.S., and prospective studies in other populations are encouraged.

\section{Conclusion}

This study demonstrated that the median survival times of CRC patients with liver metastases, lung metastases, bone metastases, and brain metastases were 12.00 months (95\% Cl: 11.71-12.29 months), 10.00 months ( $95 \% \mathrm{Cl}$ : $9.57-10.43$ months), 5.00 months (95\% Cl: $4.47-5.53$ months), and 3.00 months (95\% Cl: $2.31-3.70$ months), respectively. Older age and no surgery at the primary site were identified as the homogeneous prognostic factors of the four patterns of metastases. The calibration curves and Cindexes exhibited good performance for predicting the OS of CRC patients with distant metastases. Four nomograms for predicting OS probabilities in CRC patients were established, and all nomograms showed good accuracy and can be used as tools for clinicians to predict the prognosis of CRC patients with distant metastases.

\section{Abbreviations}

CRC

colorectal cancer

SEER

Surveillance, Epidemiology, and End Results

$\mathrm{NCl}$

National Cancer Institute

SD

standard deviation

$\mathrm{ROC}$

receiver operating characteristics 
AUC

area under the curve

SPSS

Statistical Package for the Social Sciences

CEA

carcinoembryonic antigen

\section{Declarations}

\section{Ethics approval and consent to participate}

The present study was exempt from the ethical review of the ethics board of the First Affiliated Hospital of Chongqing Medical University.

\section{Consent for publication}

Not applicable.

\section{Availability of data and materials}

The data that support the findings of this study are available from the corresponding author upon reasonable request.

\section{Conflict of interest:}

The authors declare that they have no conflict of interest.

\section{Funding:}

This project was supported by Innovation Research group in Colleges and Universities Program of Chongqing Municipal Education Commission (No. CXQT20012) and Postgraduate Tutor Team Development Program of Chongqing Municipal Education Commission (No. dstd201807).

\section{Authors' contributions}

HW and WZ designed the study. HW and MZ collected the data. HW, XS and MZ analysed the data. KQ and WZ organized the manuscript. HW, XS and MZ reviewed the papers and revised the manuscript. All the authors read and approved the final manuscript. All authors contributed to data analyses and the drafting and revising of the paper and agree to be accountable for all aspects of the work.

\section{Acknowledgments}

None. 


\section{References}

1. Bray F, Ferlay J, Soerjomataram I, Siegel RL, Torre LA, Jemal A. Global cancer statistics 2018: GLOBOCAN estimates of incidence and mortality worldwide for 36 cancers in 185 countries. CA Cancer J Clin. 2018;68(6):394-424.

2. van der Geest LG, Lam-Boer J, Koopman M, Verhoef C, Elferink MA, de Wilt JH. Nationwide trends in incidence, treatment and survival of colorectal cancer patients with synchronous metastases. Clin Exp Metastasis. 2015;32(5):457-65.

3. Qiu M, Hu J, Yang D, Cosgrove DP, Xu R. Pattern of distant metastases in colorectal cancer: a SEER based study. Oncotarget. 2015;6(36):38658-66.

4. Baek S-J, Hur H, Min B-S, Baik S-H, Lee K-Y, Kim N-K. The characteristics of bone metastasis in patients with colorectal cancer: a long-term report from a single institution. World J Surg. 2016;40(4):982-6.

5. Manfredi S, Lepage C, Hatem C, Coatmeur O, Faivre J, Bouvier AM. Epidemiology and management of liver metastases from colorectal cancer. Ann Surg. 2006;244(2):254-9.

6. Michl M, Thurmaier J, Schubert-Fritschle G, Wiedemann M, Laubender RP, Nuessler NC, et al. Brain metastasis in colorectal cancer patients: survival and analysis of prognostic factors. Clin Colorectal Cancer. 2015;14(4):281-90.

7. Engstrand J, Nilsson H, Stromberg C, Jonas E, Freedman J. Colorectal cancer liver metastases - a population-based study on incidence, management and survival. BMC Cancer. 2018;18(1):78.

8. Gu XD, Cai YT, Zhou YM, Li ZY, Xiang JB, Chen ZY. Prognostic factors and multidisciplinary treatment modalities for brain metastases from colorectal cancer: analysis of 93 patients. BMC Cancer. 2015;15(1):902.

9. Sanvarinda P, Mingphruedhi S, Jirajarus M, Chengtawee P, Sirachainan E. Prognostic factors of survival outcomes in colorectal cancer patients with liver metastasis. Ann Oncol. 2017;28(Suppl 3):iii106-7.

10. Bartolini I, Ringressi MN, Melli F, Risaliti M, Brugia M, Mini E, et al. Analysis of prognostic factors for resected synchronous and metachronous liver metastases from colorectal cancer. Gastroenterol Res Pract. 2018;2018:5353727.

11. Pietrantonio F, Aprile G, Rimassa L, Franco P, Lonardi S, Cremolini C, et al. A new nomogram for estimating survival in patients with brain metastases secondary to colorectal cancer. Radiother Oncol. 2015;117(2):315-21.

12. Huang $Y$, Zhao M, Yin J, Lu T, Yang X, Yuan G, et al. Pulmonary metastasis in newly diagnosed colonrectal cancer: a population-based nomogram study. Int J Colorectal Dis. 2019;34(5):867-78.

13. Luo D, Liu Q, Yu W, Ma Y, Zhu J, Lian P, et al. Prognostic value of distant metastasis sites and surgery in stage IV colorectal cancer: a population-based study. Int J Colorectal Dis. 2018;33(9):1241-9.

14. Yang L, He W, Xie Q, Liu S, Kong P, Jiang C, et al. Brain metastases in newly diagnosed colorectal cancer: a population-based study. Cancer Manag Res. 2018;10:5649-58. 
15. Kim BH, Park HJ, Kim K, Han SW, Kim TY, Jeong SY, et al. Novel graded prognostic assessment for colorectal cancer patients with brain metastases. Int J Clin Oncol. 2018;23(6):1112-20.

16. Lei S, Ge Y, Tian S, Cai B, Gao X, Wang N, et al. Colorectal Cancer Metastases to Brain or Bone and the Relationship to Primary Tumor Location: a Population-Based Study. J Gastrointest Surg. 2019.

17. Bostel T, Forster R, Schlampp I, Sprave T, Bruckner T, Nicolay NH, et al. Spinal bone metastases in colorectal cancer: a retrospective analysis of stability, prognostic factors and survival after palliative radiotherapy. Radiat Oncol. 2017;12(1):115.

18. Dupre A, Malik HZ, Jones RP, Diaz-Nieto R, Fenwick SW, Poston GJ. Influence of the primary tumour location in patients undergoing surgery for colorectal liver metastases. Eur J Surg Oncol. 2018;44(1):80-6.

19. Khattak MA, Martin HL, Beeke C, Price T, Carruthers S, Kim S, et al. Survival differences in patients with metastatic colorectal cancer and with single site metastatic disease at initial presentation: results from South Australian clinical registry for advanced colorectal cancer. Clin Colorectal Cancer. 2012;11(4):247-54.

20. Imaizumi J, Shida D, Narita Y, Miyakita Y, Tanabe T, Takashima A, et al. Prognostic factors of brain metastases from colorectal cancer. BMC Cancer. 2019;19(1):755.

21. Tapia Rico G, Price TJ, Karapetis C, Piantadosi C, Padbury R, Roy A, et al. Brain metastasis in advanced colorectal cancer: results from the South Australian metastatic colorectal cancer (SAmCRC) registry. Cancer Biol Med. 2017;14(4):371-6.

22. Chou CL, Chang SC, Lin TC, Chen WS, Jiang JK, Wang HS, et al. Differences in clinicopathological characteristics of colorectal cancer between younger and elderly patients: an analysis of 322 patients from a single institution. Am J Surg. 2011;202(5):574-82.

23. Zhao L, Bao F, Yan J, Liu H, Li T, Chen H, et al. Poor prognosis of young patients with colorectal cancer: a retrospective study. Int J Colorectal Dis. 2017;32(8):1147-56.

24. Anele CC, Askari A, Navaratne L, Patel K, Jenkin JT, Faiz OD, et al. The association of age with the clinicopathological characteristics and prognosis of colorectal cancer: a UK single-centre retrospective study. Colorectal Dis. 2020;22(3):289-97.

25. Kocian P, Svobodova I, Krejci D, Blaha M, Gurlich R, Dusek L, et al. Is colorectal cancer a more aggressive disease in young patients? A population-based study from the Czech Republic. Cancer Epidemiol. 2019;63:101621.

26. McKay A, Donaleshen J, Helewa RM, Park J, Wirtzfeld D, Hochman D, et al. Does young age influence the prognosis of colorectal cancer: a population-based analysis. World J Surg Oncol. 2014;12:370.

27. Li M, Li JY, Zhao AL, Gu J. Do young patients with colorectal cancer have a poorer prognosis than old patients? J Surg Res. 2011;167(2):231-6.

28. Yang L, Yang X, He W, Liu S, Jiang C, Xie K, et al. Comparisons of metastatic patterns of colorectal cancer among patients by age group: a population-based study. Aging. 2018;10(12):4107-19.

29. Okumura T, Boku N, Hishida T, Ohde Y, Sakao Y, Yoshiya K, et al. Surgical Outcome and Prognostic Stratification for Pulmonary Metastasis From Colorectal Cancer. Ann Thorac Surg. 2017;104(3):979- 
87.

30. Ma ZH, Wang YP, Zheng WH, Ma J, Bai X, Zhang Y, et al. Prognostic factors and therapeutic effects of different treatment modalities for colorectal cancer liver metastases. World J Gastrointest Oncol. 2020;12(10):1177-94.

31. Luo T, Wang Y, Shan X, Bai Y, Huang C, Li G, et al. Nomogram based on homogeneous and heterogeneous associated factors for predicting distant metastases in patients with colorectal cancer. World J Surg Oncol. 2021;19(1):30.

32. Shibutani M, Maeda K, Nagahara H, Ohtani H, Sakurai K, Toyokawa T, et al. Significance of CEA and CA19-9 combination as a prognostic indicator and for recurrence monitoring in patients with stage II colorectal cancer. Anticancer Res. 2014;34(7):3753-8.

33. Jelski W, Mroczko B. Biochemical Markers of Colorectal Cancer - Present and Future. Cancer Manag Res. 2020;12:4789-97.

34. Locker GY, Hamilton S, Harris J, Jessup JM, Kemeny N, Macdonald JS, et al. ASCO 2006 update of recommendations for the use of tumor markers in gastrointestinal cancer. J Clin Oncol. 2006;24(33):5313-27.

35. Han L, Dai W, Mo S, Xiang W, Li Q, Xu Y, et al. Nomogram to predict the risk and survival of synchronous bone metastasis in colorectal cancer: a population-based real-world analysis. Int J Colorectal Dis. 2020.

36. Liu F, Zhao J, Xie J, Xie L, Zhu J, Cai S, et al. Prognostic risk factors in patients with bone metastasis from colorectal cancer. Tumour Biol. 2016.

\section{Figures}




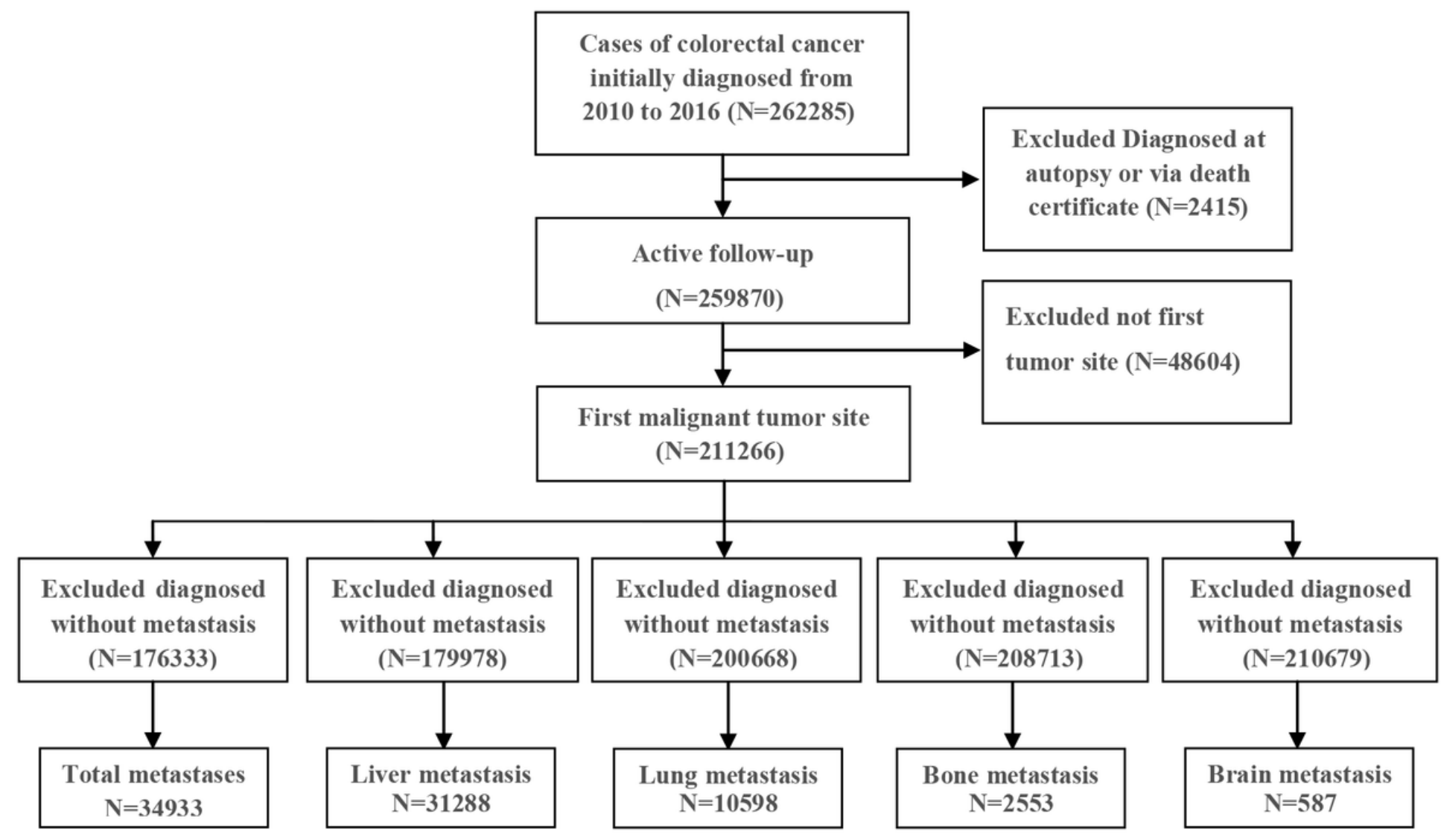

Figure 1

Flowchart of the colorectal cancer patient selection. 


\section{Overall Survival}

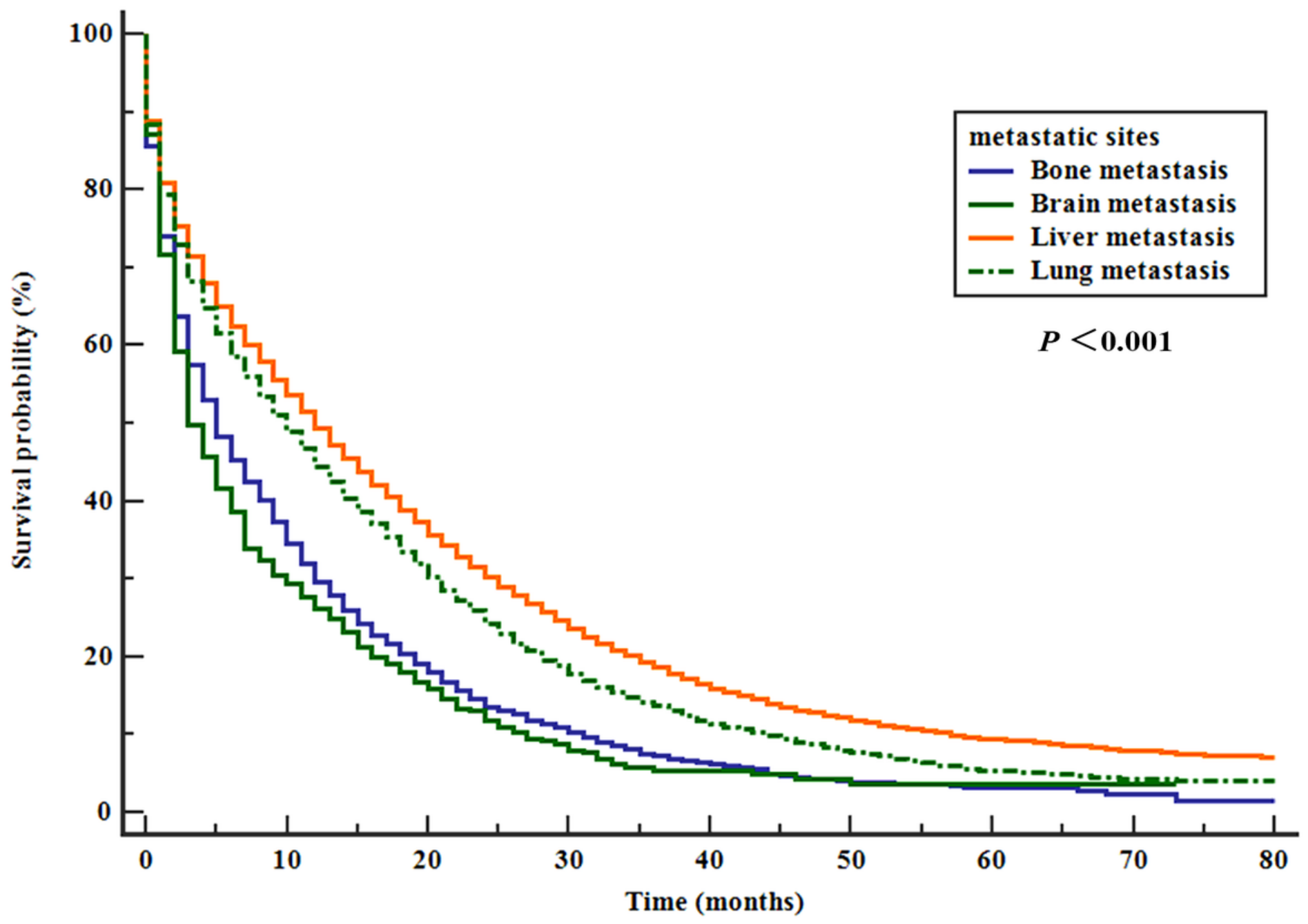

Figure 2

Kaplan-Meier analysis of overall survival in colorectal cancer patients with different distant metastases. 


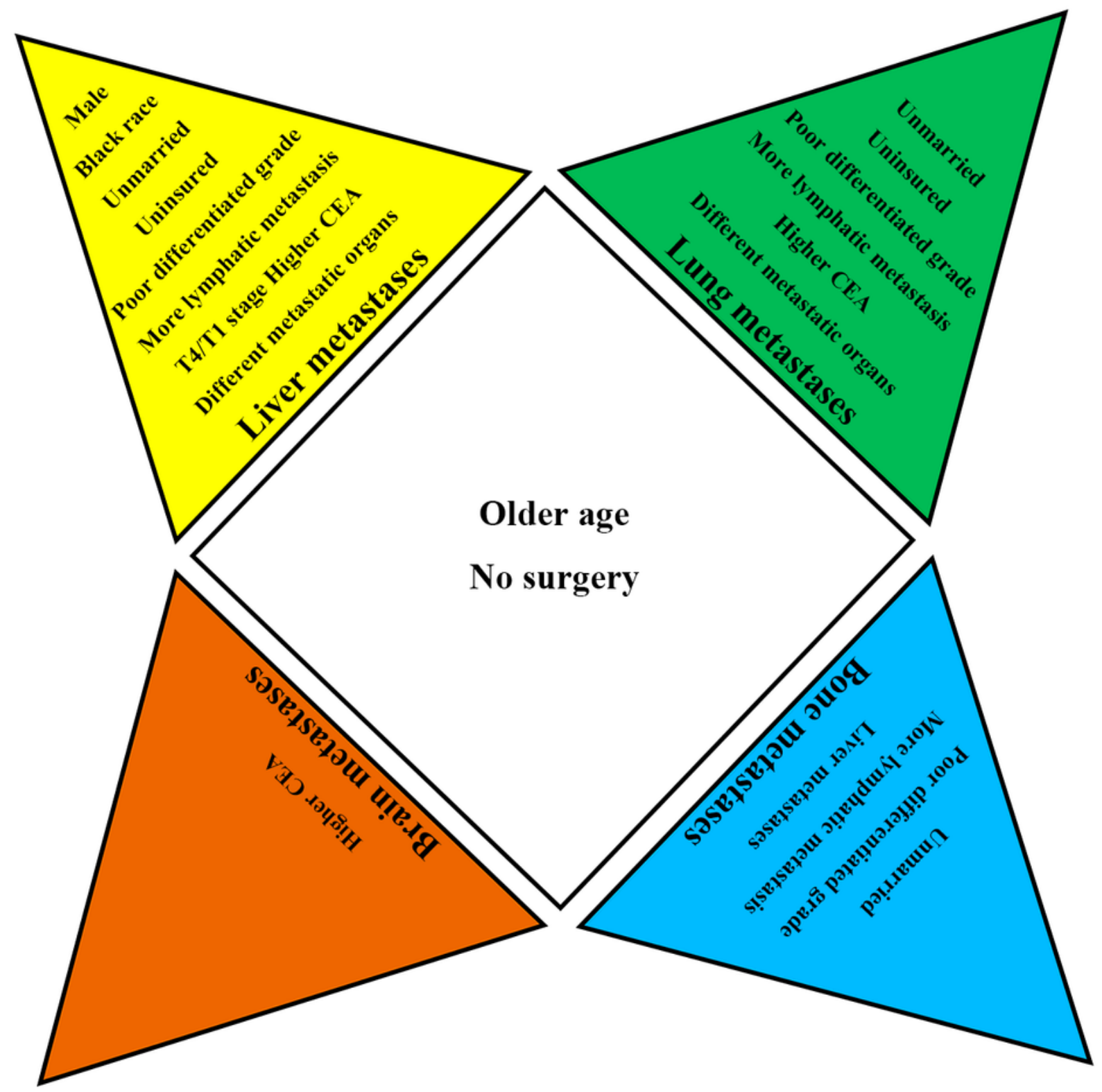

Figure 3

Homogeneous and heterogenous associated prognostic factors of different distant metastases in colorectal cancer patients. Older age and no surgery were the homogeneous associated prognostic factors for four types of distant metastases. The factors listed in the angle exhibited the specific prognostic factors that associated with each type of metastases. 

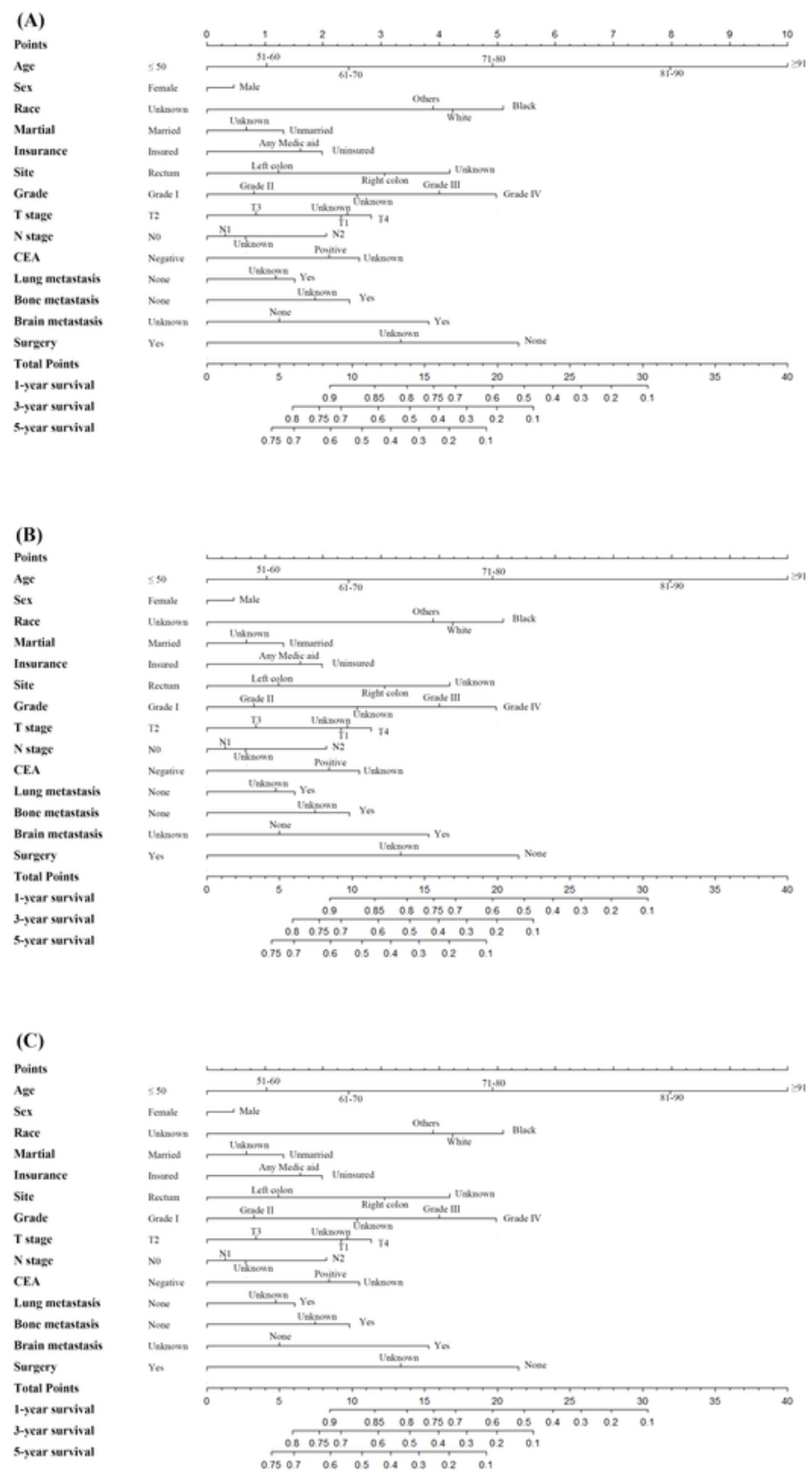

(D)

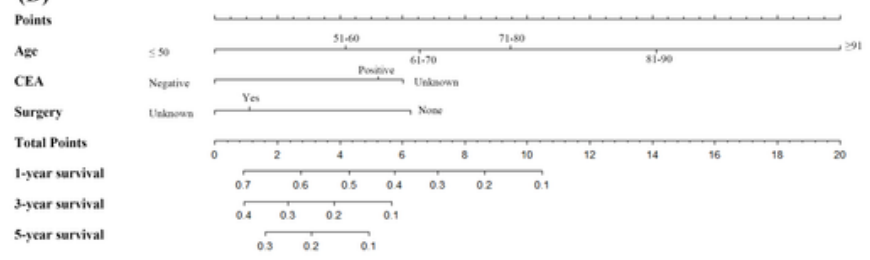

\section{Figure 4}

Nomogram for predicting the 1-, 3-, and 5-year overall survival rates of colorectal cancer patients with liver metastases (A), lung metastases (B), bone metastases (C), and brain metastases (D), respectively. 

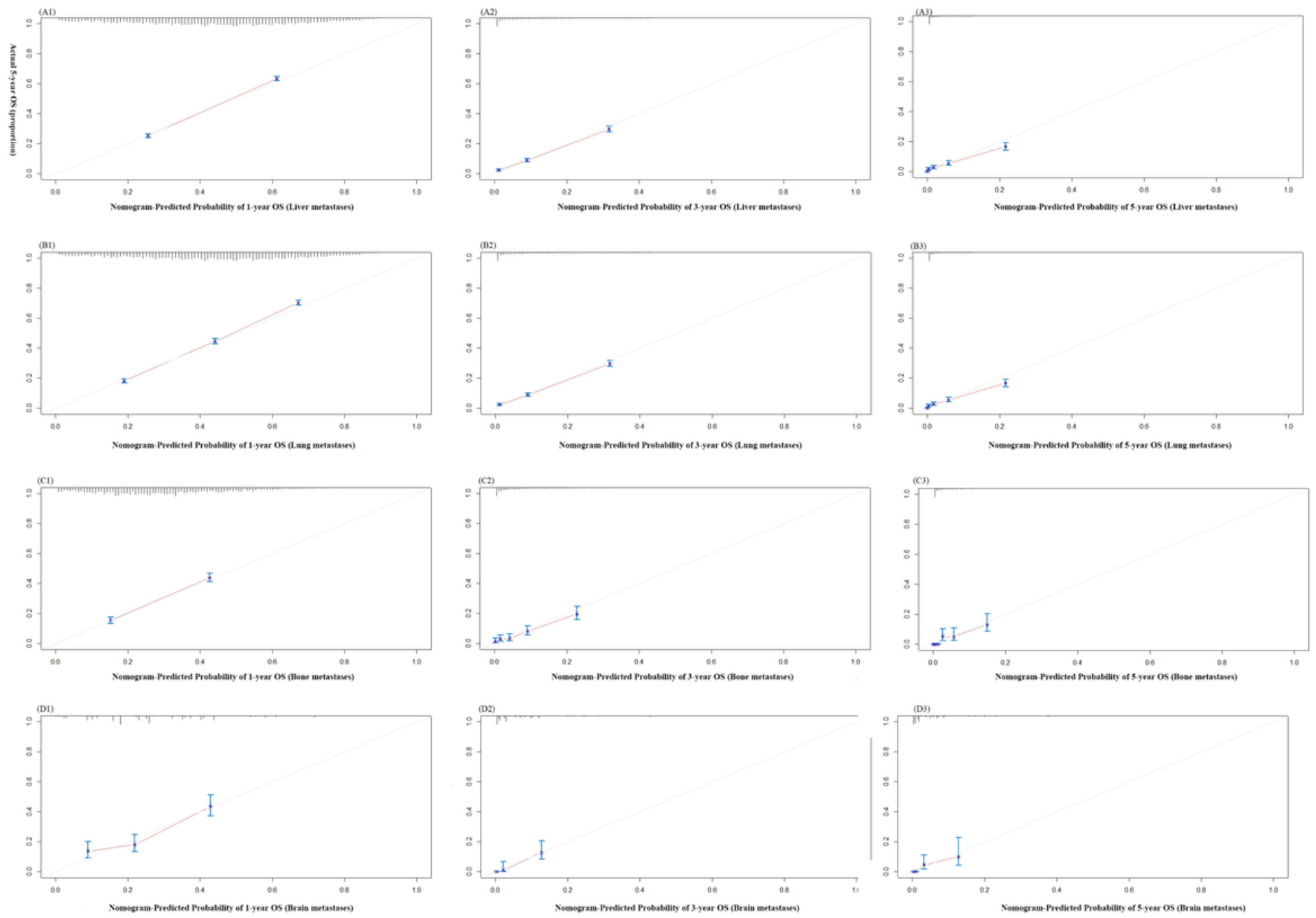

\section{Figure 5}

The calibration curve for assessing the calibration and discrimination of the nomogram in predicting 1-, 3-, and 5-year survival probabilities of colorectal cancer patients with liver metastases (A1-A3), lung metastases (B1-B3), bone metastases (C1-C3), and brain metastases (D1-D3), respectively.

\section{Supplementary Files}

This is a list of supplementary files associated with this preprint. Click to download.

- supportinformationTable.doc 